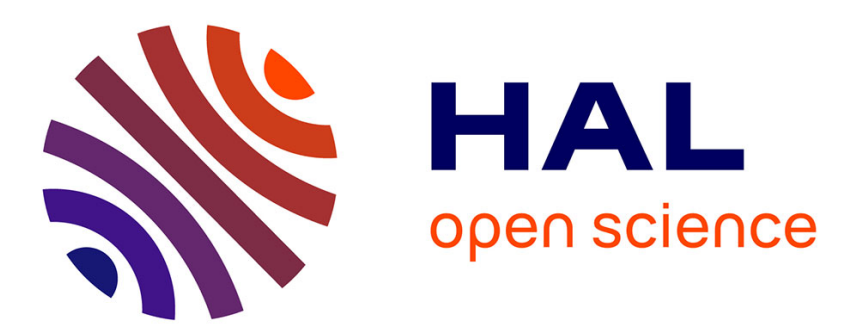

\title{
Absolute iodine (I2) standards measured by means of Fourier transform spectroscopy
}

\author{
S. Gerstenkorn, P. Luc
}

\section{To cite this version:}

S. Gerstenkorn, P. Luc. Absolute iodine (I2) standards measured by means of Fourier transform spectroscopy. Revue de Physique Appliquée, 1979, 14 (8), pp.791-794. 10.1051/rphysap:01979001408079100 . jpa-00244661

\section{HAL Id: jpa-00244661 https://hal.science/jpa-00244661}

Submitted on 1 Jan 1979

HAL is a multi-disciplinary open access archive for the deposit and dissemination of scientific research documents, whether they are published or not. The documents may come from teaching and research institutions in France or abroad, or from public or private research centers.
L'archive ouverte pluridisciplinaire HAL, est destinée au dépôt et à la diffusion de documents scientifiques de niveau recherche, publiés ou non, émanant des établissements d'enseignement et de recherche français ou étrangers, des laboratoires publics ou privés. 


\title{
Absolute iodine ( $\left.\mathbf{I}_{2}\right)$ standards measured by means of Fourier transform spectroscopy
}

\author{
S. Gerstenkorn and P. Luc \\ Laboratoire Aimé Cotton, C.N.R.S. II, Bâtiment 505, 91405 Orsay, France
}

(Reçu le 7 mai 1979, accepté le 16 mai 1979)

\begin{abstract}
Résumé. - Le spectre d'absorption de la molécule de l'iode, enregistré par spectroscopie de Fourier dans le visible, a été étalonné à l'aide de la méthode de l'étalon interne. Il en résulte que les nombres d'ondes publiés dans l'atlas de la molécule de l'iode couvrant le domaine $14800-20000 \mathrm{~cm}^{-1}$ doivent être corrigés. En retranchant $0,0056 \mathrm{~cm}^{-1}$ aux nombres d'ondes publiés, on obtient les valeurs absolues des nombres d'ondes du spectre de l'iode avec une incertitude estimée être de l'ordre de $\pm 0,002 \mathrm{~cm}^{-1}$.
\end{abstract}

\begin{abstract}
The internal standard method has been used to calibrate the absorption spectrum of the iodine molecule recorded in the visible by means of Fourier spectroscopy. The result is that the wavenumbers previously published in the iodine-atlas extending from 14800 to $20000 \mathrm{~cm}^{-1}$ must be corrected by substracting $0.0056 \mathrm{~cm}^{-1}$ from all wavenumbers. The accuracy of the absolute wavenumbers obtained in this way is estimated $\pm 0.002 \mathrm{~cm}^{-1}$.
\end{abstract}

1. Introduction. - Recently we have published an atlas of the iodine absorption spectrum to provide precise standards, specially for high resolution works [1]. This atlas extends from 14800 to $20000 \mathrm{~cm}^{-1}$ and contains more than 22000 wavenumbers. The accuracy of the differences between the wavenumbers given in this atlas is $0.0007 \mathrm{~cm}^{-1}$ (reference [1], p. 24) which corresponds to an uncertainty of about $(1 / \sqrt{2}) \times 0.0007 \mathrm{~cm}^{-1}=0.0005 \mathrm{~cm}^{-1}$ of each wavenumber involved in these differences. However, the absolute values of the wavenumbers were estimated to be only defined within $\pm 0.006 \mathrm{~cm}^{-1}$ (reference [1], p. 24), which is one order of magnitude lower than the internal coherence of these wavenumbers. This discrepancy is due to the method used to calibrate the iodine spectrum : although we recorded simultaneously the absorption spectrum of the iodine molecule and the atomic emission spectrum of uranium (Fig. 1), these two spectra were given by two different sources. With this arrangement small misalignements between the two sources always occur and systematic errors in the calibration of the wavenumbers are unavoidable. The absolute wavenumbers of the uranium spectrum were themselves found by comparison with krypton standards, and of course, are also liable to some uncertainties [2]. At that time, we chose this method - called the external standard method [3] because the internal standard method could not be used; in this method some iodine lines whose absolute wavenumbers are known very precisely

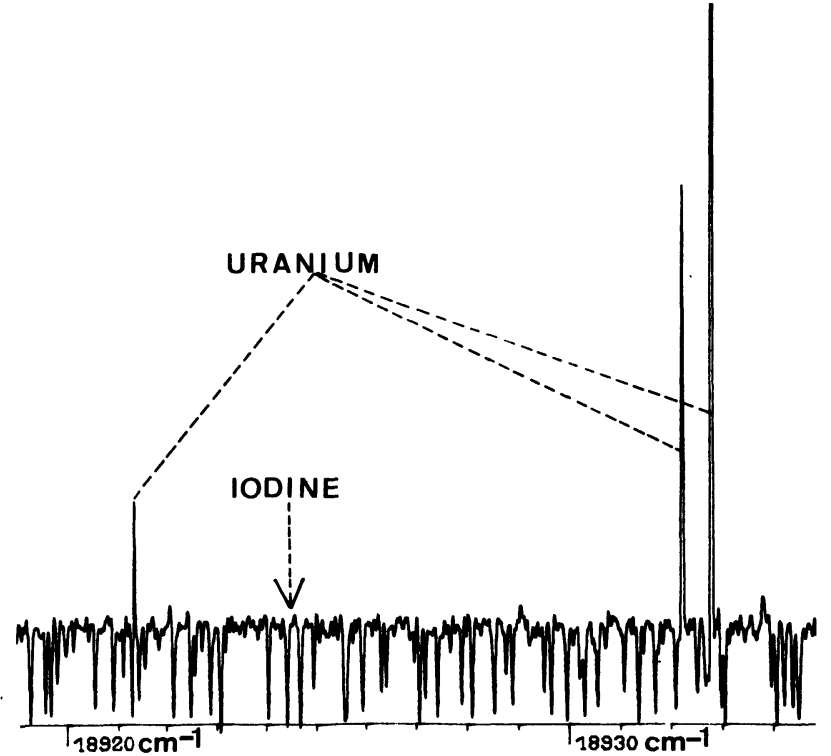

Fig. 1. - Calibration of the iodine spectrum by means of the uranium spectrum (external standard method).

from the studies of hyperfine structure are used as standards. The reason for this is that one cannot be sure that the centre of gravity of a given recorded line (in which the hfs components are blended) is really the centre of gravity of the measured hyperfine structure of this line. Fortunately, recent progress 
both in the assignment of the iodine spectrum [4], [5] and studies of the hyperfine structure of numerous iodine lines [6-14] allow us now to have recourse to the internal standard method to calibrate the iodine spectrum. First, to avoid the problem of possible blends, we have not used the directly measured wavenumbers of the iodine lines but in all cases we use the wavenumbers calculated from the new molecular constants derived from the careful analysis of the unblended lines distributed through the whole spectrum [5]. (For lines with $J$ values lower than 100, the agreement between calculated and measured wavenumbers are mainly limited by the noise present in the spectrum [5].) Secondly, knowing the hyperfine structure of numerous iodine lines [6-14], and the absolute wavenumber of one hyperfine component in each hyperfine structure, it is easy to calculate the absolute wavenumber of the centre of gravity of these hyperfine structure and to use them as standards.

Comparison between these two sets of calculated wavenumbers (Table II) will enable us to determine the absolute wavenumbers of the iodine absorption spectrum and also give an estimate of the consistency of the molecular constants recently published [5].

2. Determination of the centre of gravity of the the iodine lines. - 2.1 FROM THE HYPERFINE STRUCTURES. - According to the parity of the lines the number of hyperfine components is 15 if $J$ is even and 21 if $J$ is odd [15]. For lines with $J>30$ the intensities

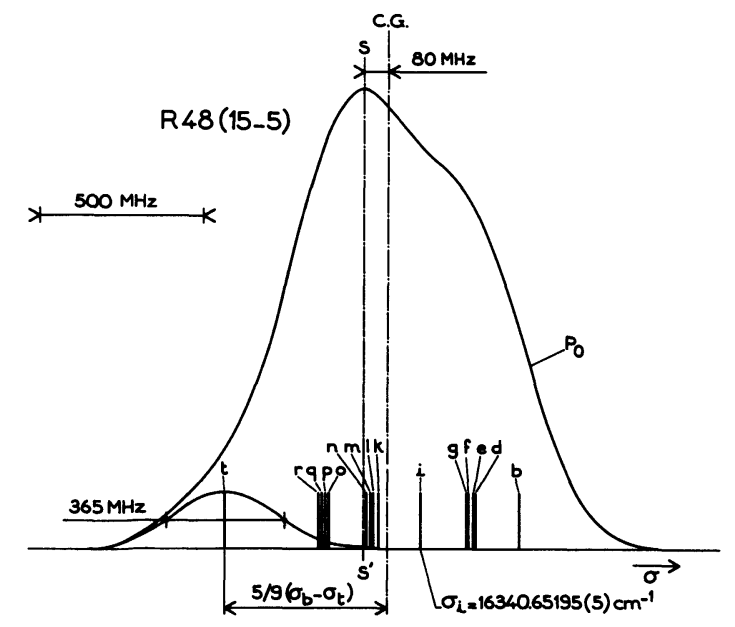

Fig. $2 a$. $-P_{0}$ : resulting profile of the 15 hyperfine components belonging to the R48 (15-5) transition.

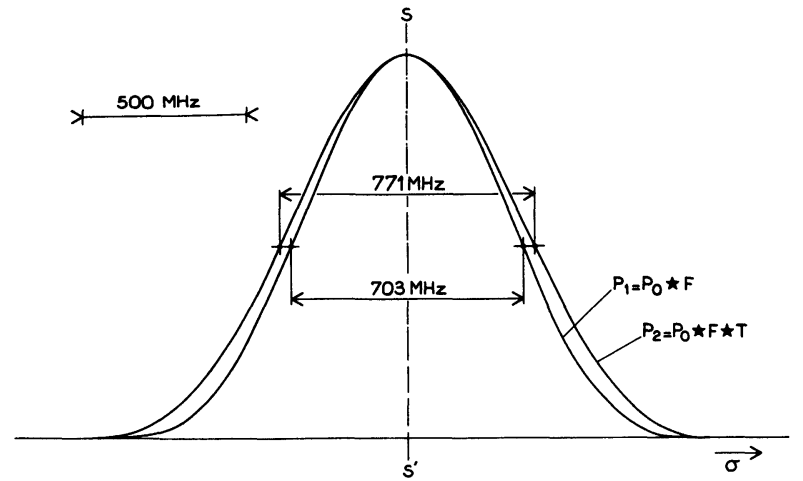

Fig. $2 b .-P_{1}$ : resulting profile of the convolution product of $P_{0}$ with $F$ ( $F$ apparatus function of the Fourier interferometer).

$P_{2}$ : resulting profile of the convolution product of $P_{0}$ with $F$ and $T$ ( $T$ apparatus function due to the finite aperture of the interferometer). The effect of $F$ or $T$ is enough to efface any trace of the disymmetrical profile $P_{0}$.

of these 15 or 21 components may be considered sensibly equal and, in both cases, the centre of gravity of an iodine line is situated to a good approximation, at a point at $5 / 9$ of the distance between the components labelled « $\mathrm{t}$ " and $" \mathrm{~b}$ " (see Figs. $2 a$ and $3 a$ and Table I). (For lines with low values of $J$, the intensities of the hyperfine components are very unequal and the resulting profile of the sum of these components may be very asymmetrical [14]. For this reason we have chosen, for our calibration purposes, only transitions with $J$ values higher than 30 .)

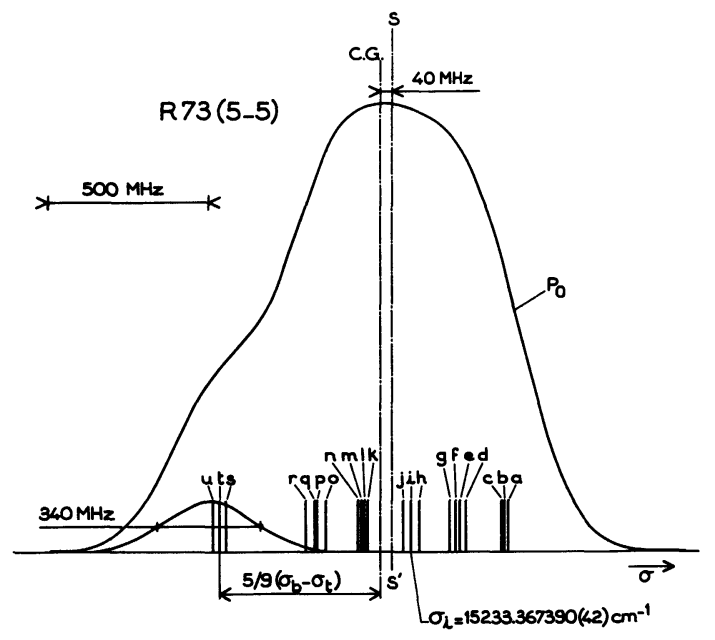

Fig. $3 a .-P_{0}$ resulting profile of the 21 hyperfine components belonging to the R73 (5-5) transition.

Table I. - Wavenumbers of the centres of gravity of iodine lines.

\begin{tabular}{ccc} 
& \multicolumn{2}{c}{$\begin{array}{c}\text { Measured distances } \\
(\mathrm{MHz})\end{array}$} \\
Transitions & $\sigma_{\mathrm{b}}-\sigma_{\mathrm{t}}$ & $\sigma_{\mathrm{i}}-\sigma_{\mathrm{t}}$ \\
- & $-\overline{-}$ & $-\bar{c}$ \\
R48 (15-5) [10] & 874.1 & 582.3 \\
R73 (5-5) [6] & 879.6 & 588.6
\end{tabular}

$$
\begin{gathered}
\sigma_{\mathrm{i}}\left(\begin{array}{c}
\text { measured }) \\
\left(\mathrm{cm}^{-1}\right)
\end{array}\right. \\
-- \\
16340.65195 \quad(5) \\
15233.367390(42)
\end{gathered}
$$$$
\sigma^{\text {c.G. }}(\text { calculated) }
$$$$
\left(\mathrm{cm}^{-1}\right)
$$ 


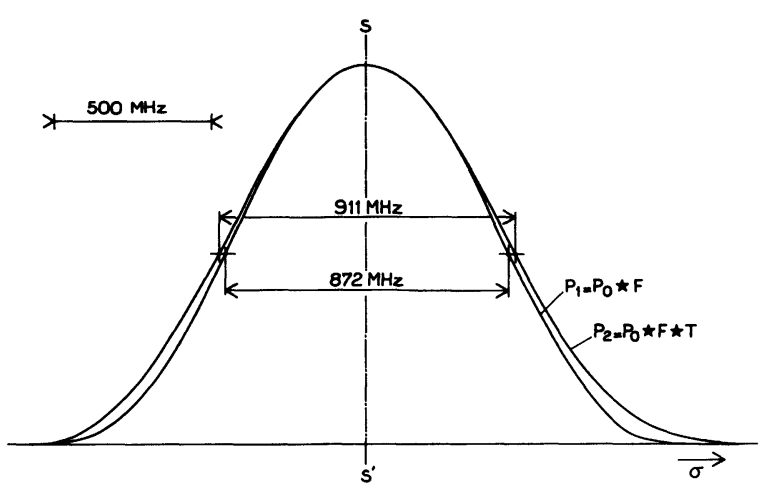

Fig. $3 b$. - Here again, using the same apparatus functions $F$ and $T$ as those of figure $2 b$, the disymmetrical profile $P_{0}$ completely vanishes.

\subsection{FROM THE FOURIER SPECTROSCOPY SPECTRUM. -} The recorded profiles of the iodine lines arise from the convolution of three functions : the source profile $P_{0}$, the Fourier apparatus function $F=\sin x / x$ and a rectangular function $T$ due to the finite aperture of the Fourier interferometer.

Figures $2 a$ and $3 a$ give examples of the complex resulting profiles in the case of a line with 15 components (Fig. 2a) and 21 components (Fig. 3a). Each hyperfine component is supposed to have a gaussian profile which is, in case of weak absorption, a good approximation [15]. The calculated Doppler widths, at room temperature are respectively, $365 \mathrm{MHz}$ for the transition R48(15-5) and $340 \mathrm{MHz}$ for the transition R73 (5-5). (It can be seen from the figures $2 a$ and $3 a$ that the maximum of the source profile $P_{0}$ and the centre of gravity of this complex profile do not coincide.) The width of the two apparatus functions were matched to be sensible equal $(450 \mathrm{MHz})$ and comparable to the width of hyperfine component $(350 \mathrm{MHz})$. The calculated profiles $P_{2}=P_{0} * F * T$ are now almost completely symmetrical and the discrepancies between the positions of the maximum and the centre of gravity of the lines are negligible. Thus, with an effective resolving power of the order of $10^{6}$, the algorithm used to determine the wavenumbers of the iodine spectrum [16] by observing the maximum of the lines does not introduce, at least for lines with $J$ values higher than 30 , any detectable systematic error in the measurements. (For higher resolving powers or for low $J$ values in the vicinity of the band origins, it is not always the case [14].)

3. Results. - In column 2 of table II are listed the measured wavenumbers obtained by the external standard method using the uranium spectrum as shown in figure 1 . The assignments of these lines are given in column 1. Some of the lines whose hyperfine structures are known [6-14], are either blended or not observed at all in our experimental conditions as for example the transition R48 (15-5) of figure 2. As mentioned above, in order to overcome these difficulties and to make valid comparison with the calculated wavenumbers of the centre of gravity of the hyperfine patterns, we give in column 3 the calculated wavenumbers resulting from the whole analysis of the B-X system [5]. The molecular constants used to calculate these wavenumbers are given in reference [5], table V. In column 4 are the measured absolute values of the wavenumbers of one hyperfine component belonging to the hyperfine structure of the line under consideration and in column 5 are the centre of gravity of the lines calculated accordingly to the procedure described in paragraph 2.1 , table I. Finally, in column 6 are the differences

$$
\left(\sigma_{\text {calculated }}^{\text {Fourier }}-\sigma_{\text {calculated }}^{\text {C.G.G. }}\right)
$$

between the two sets of calculated wavenumbers : the first set (column 3) is based on Fourier spectroscopy data measured at Laboratoire Aimé Cotton and the second set (column 5) is taken from recent laser spectroscopy data given in numerous publica-

Table II. - Calibration of the iodine spectrum by means of the " internal standard method».

Fourier Spectroscopy $\left(\mathrm{cm}^{-1}\right)$

\begin{tabular}{|c|c|c|}
\hline Transition & $\begin{array}{c}\sigma \text { Fourier } \\
\text { observed } \\
\text { Atlas [1] [4] }\end{array}$ & $\begin{array}{c}\sigma_{\text {caurier }}^{\text {Foluated }} \\
\text { Global fit [5] }\end{array}$ \\
\hline - & - & - \\
\hline $\mathrm{R} 73(5-5)$ & 15233.3709 (6) & 15233.3707 \\
\hline P33 (6-3) & & 15797.9814 \\
\hline R127 (11-5) & not observed & 15798.0046 \\
\hline P48 (11-3) & & 16340.6363 \\
\hline R48 (15-5) & 16340.6439 (5) & 16340.6542 \\
\hline R47 (9-2) & & 16340.6592 \\
\hline P117 (21-1) & $17594.8057(10)$ & $17594 ' 8043$ \\
\hline R76 (40-0) & $19194.6176(5)$ & 19194.6166 \\
\hline R98 (58-1) & $19429.7382(20)$ & 19429.7365 \\
\hline
\end{tabular}

Laser spectroscopy $\left(\mathrm{cm}^{-1}\right)$

$\begin{gathered}\text { Measured absolute values } \\ \text { of the wavenumbers } \\ \text { of hyperfine components }\end{gathered}$
$-\overline{\sigma_{\mathrm{i}}=} 15233.367390(42)[6]$
$\sigma_{\mathrm{i}}=15797.97962[7]$
$\sigma_{\mathrm{i}}=15798.00295[8]$
$\sigma_{\mathrm{i}}=16340.63480[9]$
$\sigma_{\mathrm{i}}=16340.65195[10]$
$\sigma_{\mathrm{i}}=16340.65805[10]$
$\sigma_{\mathrm{b}}=17594.8120[11]$
$\sigma_{\mathrm{t}}=19194.5933[11]$
not published

Measured absolute values of hyperfine components$$
\sigma_{\mathrm{i}}=15233.367390(42)[6]
$$$$
\sigma_{\mathrm{i}}=15797.97962[7]
$$$$
\sigma_{\mathrm{i}}=15798.00295[8]
$$$$
\sigma_{\mathrm{i}}=16340.63480[9]
$$$$
\sigma_{\mathrm{i}}=16340.65195[10]
$$

$$
\begin{gathered}
\text { Differences } \\
\text { ourier } \\
\text { calculated } \sigma_{\text {calc. }}^{\text {Cag. }} \\
\left(\mathrm{cm}^{-1}\right) \\
- \\
+0.0066 \\
+0.0051 \\
+0.0050 \\
+0.0047 \\
+0.0055 \\
+0.0045 \\
+0.0051 \\
+0.0076 \\
+0.0065
\end{gathered}
$$
$\sigma \underset{\text { calculated }}{\text { Fourier }} \sigma$ calc.

$$
\text { Average } \begin{aligned}
: & +0.0056 \\
& \pm 0.0010
\end{aligned}
$$


tions [6-14]. The calculated wavenumbers obtained by means of Fourier spectroscopy are systematically higher by an average amount $\delta=0.0056 \mathrm{~cm}^{-1}$ than the absolute wavenumbers determined by laser spectroscopy.

4. Discussion and conclusion. - The accuracy of the differences between the wavenumbers published in the iodine atlas was estimated to be of the order of $\pm 0.0007 \mathrm{~cm}^{-1}$ for the strongest unblended lines and was based on the consideration of constant differences according to the combination principle. (Reference [1], Table II.) However, the use of the combination principle has to be made with some caution. Indeed, if all the measured wavenumbers $\sigma$ of a given spectrum are shifted by a constant quantity $\delta$, or either by a quantity proportional to $\sigma$, that is to say :

$$
\sigma_{\text {observed }}=\sigma_{\text {true }}+\delta \text { or } \sigma_{\text {observed }}=\sigma_{\text {true }}(1+\varepsilon),
$$

$\varepsilon$ being a constant factor, then the differences between pairs of lines obeying the combination principle will appear as constant : in other words observation of constant differences does not put in evidence a shift of a constant quantity, which is obvious; but also an error proportional to the wavenumbers cannot be detected. Now, precisely systematic errors in Fourier spectroscopy are often proportional to the frequencies [3]. To eliminate this source of errors, we have calibrated the iodine spectrum by means of the uranium spectrum, but the constant difference

$$
\delta=0.0056 \pm 0.0010 \mathrm{~cm}^{-1}
$$

found on average between the calculated wavenumbers (column 6, Table II) shows that the calibration by means of the uranium spectrum was not adequate. However, the standard deviation of $\pm 0.0010 \mathrm{~cm}^{-1}$ which characterizes the quantity $\delta$ is a definite proof that the differences between the measured wavenumbers are of the order of this standard deviation, which in turn, is comparable to the uncertainties produced by the noise present throughout the whole spectrum (reference [1], p. 22). Thus, to obtain the absolute wavenumbers of the absorption spectrum of iodine, it is necessary to correct the published wavenumbers of the atlas by subtracting $0.0056 \mathrm{~cm}^{-1}$ from all these wavenumbers. The wavenumbers calculated from the molecular constants given in reference [5], still represent the absolute value of the iodine wavenumbers providing that an amount of $0.0056 \mathrm{~cm}^{-1}$ is subtracted from the values of the band origins $\sigma_{\mathrm{ov}}$ given in table $\mathrm{V}$ of reference [5].

Finally, comparison between the absolute wavenumbers now determinated by the internal standard method and those published by Simmons and Hougen [17], using an external standard method of calibration, namely, the thorium spectrum as standard and a grating spectrograph, shows that the wavenumbers published by these authors in their atlas of iodine extending from $18000-19000 \mathrm{~cm}^{-1}$ are also too high by an average quantity of

$$
(0.012 \pm 0.004) \mathrm{cm}^{-1} \text {. }
$$

In conclusion, it is necessary to subtract a constant value of $\delta 0.0056 \mathrm{~cm}^{-1}$ from the published wavenumbers, to obtain 22000 absolute wavenumbers in the region $14800-20000 \mathrm{~cm}^{-1}$. The accuracy of these absolute wavenumbers is $\pm 0.002 \mathrm{~cm}^{-1}$ (twice the standard deviation), the probability of an error exceeding this amount being only $5 \%$. From the measurements made by Simmons and Hougen in the region $18000-19000 \mathrm{~cm}^{-1}$, it is necessary to subtract $0.012 \mathrm{~cm}^{-1}$ and the accuracy of the absolute wavenumbers will be in this case of the order of $\pm 0.008 \mathrm{~cm}^{-1}$ which is twice better than the estimate made by these authors $\left( \pm 0.015 \mathrm{~cm}^{-1}\right)[17]$.

Acknowledgments. - The authors are much obliged to Mrs. D. Garcès who has written the convolution programs and to A. Brillet for communication his results on hyperfine studies prior to publication. We also thank Prof. D. A. Jackson for kindly reading this manuscript and giving us valuable comments.

\section{References}

[1] Gerstenkorn, S. et LuC, P., Atlas du spectre d'absorption de la molécule de l'iode entre $14800-20000 \mathrm{~cm}^{-1}$ (Editions du C.N.R.S., 15, quai Anatole-France, 75700 Paris).

[2] Gerstenkorn, S. and Luc, P., Nouv. Rev. Opt.. . (1976) 148.

[3] Guelachvili, G., Thèse, Orsay, France (1973).

[4] Gerstenkorn, S. and LuC, P., "Assignments of several iodine (I ) lines in the B-X system ", to be published in J. Mol. Spectrosc. (1979).

[5] Luc, P., « Molecular constant and Dunham parameters describing the $\mathrm{I}_{2}$ B-X system ", to be published in $\mathrm{J}$. Mol. Spectrosc. (1979).

[6] Goldsmith, J. E. M., Weber, E. W. and Hansch, T. W., Phys. Rev. Lett. 41 (1978) 1525.

Goldsmith, J. E. M., Weber, E. W., Kowalski, F) V. and Schawlow, A. L., Appl. Opt., to be published (1979) and private communication.

[7] HANes, G. R., LAPIERRE, J., BunKeR, P. R. and ShOtTon, X. C., J. Mol. Spectrosc. 39 (1971) 506.
[8] Schweitzer, W. G., Kessler, E. G., Deslattes, R. D., Layer, H. P. and Whetstone, J. R., Appl. Opt. 12 (1973) 2927.

[9] Cerez, P. and Bennett, S. J., Metrologia, to be published (1979).

[10] Brillet, A., Cerez, P., Man, N., Luquet, P., private communication (1979).

[11] Kowalski, F. V., Hawkins, R. T. and Schawlow, A. L., $J$. Opt. Soc. Am. 66 (1975) 965.

[12] Gill, P. and BennetT, S. J., Metrologia, to be published (1979).

[13] Vigué, J., Broyer, M. and Lehmann, J. C., J. Phys. B, Atom. Molec. Phys. 10 (1977) L 379.

[14] Hartmann, F., Stoeckel, F., Pique, J. P., private communication.

[15] Kroll, M. and InNes, K. K., J. Mol. Spectrosc. 36 (1970) 295.

[16] Gerstenkorn, S., Luc, P., Perrin, A. and Chauville, J., Astron. Astrophys. 58 (1977) 255.

[17] Simmons, J. D. and Hougen, J. T., J. Res. Nat. Bur. Stand. (U.S.) 81 (1977) 25. 